\title{
Assessment of continuous pain in newborns admitted to NICUs in 18 European countries
}

Kanwaljeet J. S. Anand (anandam@stanford.edu) ${ }^{1}$, Mats Eriksson ${ }^{2}$, Elaine M. Boyle ${ }^{3}$, Alejandro Avila-Alvarez ${ }^{4}$, Randi Dovland Andersen ${ }^{5}$, Kosmas Sarafidis ${ }^{6}$, Tarja Polkki ${ }^{7}$, Cristina Matos ${ }^{8}$, Paola Lago ${ }^{9}$, Thalia Papadouri ${ }^{10}$, Simon Attard-Montalto ${ }^{11}$, Mari-Liis Ilmoja ${ }^{12}$, Sinno Simons ${ }^{13}$, Rasa Tameliene ${ }^{14}$, Bart van Overmeire ${ }^{15}$, Angelika Berger ${ }^{16}$, Anna Dobrzanska ${ }^{17}$, Michael Schroth ${ }^{18}$, Lena Bergqvist ${ }^{19}$, Emilie Courtois ${ }^{20}$, Jessica Rousseau ${ }^{20}$, Ricardo Carbajal ${ }^{20}$ on behalf of the EUROPAIN survey working group of the NeoOpioid Consortium

1.Departments of Pediatrics, Anesthesiology, Perioperative \& Pain Medicine, Stanford University School of Medicine, Stanford, CA, USA

2.School of Health Sciences, Faculty of Medicine and Health, Örebro University, Örebro, Sweden

3.Department of Health Sciences, University of Leicester, Leicester, UK

4.Department of Neonatology, Complexo Hospitalario Universitario de A Coruña, Coruña, Spain

5.Department of Child \& Adolescent Health Services, Telemark Hospital, Skien, Norway

6.1st Department of Neonatology, 'Hippokrateion' General Hospital, Aristotle University of Thessaloniki, Thessalokiki, Greece

7.Children and Women Department, Oulu University Hospital, Oulu, Finland

8.Maternidade Dr. Alfredo da Costa, Lisboa, Portugal

9.Department of Woman's and Child's Health, University of Padua, Padua, Italy

10.Department of Paediatrics, Arch. Makarios III Hospital, Nicosia, Cyprus

11.Department of Paediatrics, Mater Dei Hospital, Msida, Malta

12.Department of Paediatrics, Tallinn Children's Hospital, Tallinn, Estonia

13.Department of Pediatrics, Erasmus MC-Sophia Kinderziekenhuis, Rotterdam, The Netherlands

14.Department of Neonatology, Kaunas Perinatal Center, Lithuanian University of Health Sciences, Kaunas, Lithuania

15.Cliniques Universitaires de Bruxelles, Erasme Hospital, Bruxelles, Belgium

16.Department of Pediatrics and Adolescent Medicine, Medical University Vienna, Vienna, Austria

17.Department of Neonatology, Children's Memorial Health Institute Warsaw, Warszawa, Poland

18.Department of Paediatrics, Cnopf'sche Kinderklinik, Nürnberg Children's Hospital, Nürenberg, Germany

19.Department of Clinical Science, Intervention and Technology, Karolinska Institutet, Solna, Sweden

20.Urgences Pédiatriques, Hôpital Armand Trousseau, INSERM U1 153, Université Pierre et Marie Curie Paris VI, Paris, France

\section{Keywords}

Clinical practices, Infant-newborn, Infant-premature, Neonatal intensive care units, Suffering

\section{Correspondence}

Dr. Kanwaljeet J. S. Anand, Stanford University School of Medicine, 770 Welch Road, Suite 435, Stanford, CA 94304 MC: 5876, USA.

Tel: (650) 498-6313 |

Fax: (650) 736-9186

Email: anandam@stanford.edu

\section{Received}

8 January 2017; revised 6 February 2017; accepted 21 February 2017.

DOI:10.1111/apa.13810

Trial Registration: ClinicalTrials.gov \#NCT01694745.

\begin{abstract}
Aim: Continuous pain occurs routinely, even after invasive procedures, or inflammation and surgery, but clinical practices associated with assessments of continuous pain remain unknown.

Methods: A prospective cohort study in 243 neonatal intensive care units (NICUs) from 18 European countries recorded the frequency of pain assessments, use of mechanical ventilation, sedation, analgesia or neuromuscular blockade for each neonate for up to 28 days after NICU admission. Results: Only 2113 of 6648 (31.8\%) of neonates received assessments of continuous pain, occurring variably among tracheal ventilation ( $\mathrm{TrV}, 46.0 \%)$, noninvasive ventilation (NiV, 35.0\%) and no ventilation (NoV, 20.1\%) groups ( $p<0.001)$. Daily assessments for continuous pain occurred in only 10.4\% of all neonates (TrV: 14.0\%, NiV: 10.7\%, NoV: 7.6\%; $p<0.001$ ). More frequent assessments of continuous pain occurred in NICUs with pain guidelines, nursing champions and surgical admissions (all $p<0.01$ ), and for newborns $<32$ weeks gestational age, those requiring ventilation, or opioids, sedatives-hypnotics, general anaesthetics (O-SH-GA) (all $p<0.001)$, or surgery $(p=0.028)$. Use of O-SH-GA drugs increased the odds for pain assessment in the TrV (OR:1.60, $p<0.001$ ) and NiV groups (OR:1.40, $p<0.001$ ).
\end{abstract}

Conclusion: Assessments of continuous pain occurred in less than one-third of NICU admissions and daily in only $10 \%$ of neonates. NICU clinical practices should consider including routine assessments of continuous pain in newborns.

\footnotetext{
Abbreviations

C.I., Confidence intervals; CRIB, Clinical Risk Index for Babies; EDIN, Echelle Douleur Inconfort Nouveau-né; EUROPAIN, Europeanpain-audit-in-neonates; GEE, Generalised estimating equations; IQR, Interquartile range; IUGR, Intrauterine growth retardation; NA, Not applicable; NICUs, Neonatal intensive care units; NiV, Noninvasive ventilation; NoV, No ventilation, that is breathing spontaneously; N-PASS, Neonatal Pain, Agitation and Sedation Scale; NPIs, National Principal Investigators; OR, Odds ratio; O-SH-GA, Opioids, sedative hypnotics or general anaesthetics; PCA, Postconceptual age; QIC, Quasi-likelihood under the Independence model Criterion; SD, Standard deviation; STROBE, Strengthening the reporting of observational studies in epidemiology; TrV, Tracheal ventilation.
} 


\section{Key notes}

- Neonatal pain assessments have previously focused on acute pain associated with skin-breaking procedures, but the importance of assessing continuous pain remains unknown.

- Assessments of continuous pain varied 0-100\% in neonatal intensive care units (NICUs), occurring daily in $10.4 \%$ of all neonates and at least once during their NICU stay in $31.8 \%$ neonates.

- Neonatal pain research, clinical guidelines and bedside practices should also focus on assessments of continuous pain in addition to the assessments for procedural pain.

\section{INTRODUCTION}

All newborns experience acute episodic pain or prolonged, continuous pain during admission to neonatal intensive care units (NICUs) (1,2). Untreated neonatal pain prolongs human suffering and is often associated with short-term and long-term physical, behavioural, or cognitive sequelae $(3,4)$. Conversely, some analgesic drugs can prolong mechanical ventilation (5), delay feedings (6) or impair brain growth and development (7-9). Pain needs to be assessed before treatment, but neonatal pain assessments are time- and labour-intensive and difficult to implement in routine NICU care (10-12).

Bedside nurses make global pain assessments or apply validated pain assessment tools before treating a newborn's pain or discomfort $(13,14)$, but NICU workloads may not allow bedside nurses to assess pain regularly. Most neonatal pain scales were designed to measure acute pain from skinbreaking procedures; these scales may not be clinically relevant for measuring continuous pain (15). Assessments of the continuous pain that follows invasive procedures, or inflammation and surgery, may enhance the quality of pain management, avoid untreated pain vs. unnecessary analgesia, prevent under- or overdosing of analgesics, or development of drug tolerance (16-18).

Continuous pain may be defined as pain lasting beyond the initial episode that causes tissue injury (19), mucosal stimulation (20) or inflammation $(4,21)$. Attempts to define chronic or continuous pain in newborns have not led to consistent or clinically useful definitions $(16,17)$. Identifying continuous pain is important because it may interfere with infant growth, prolong hospitalisation, alter subsequent pain perception and impair cognitive and behavioural development $(4,17)$. Few methods, however, were designed to assess continuous pain (15,22-24) and the application of assessment methods designed using acute pain models to clinical assessments of continuous pain remains controversial (25).

We hypothesized that continuous pain is not assessed routinely during NICU care, but may be assessed more frequently among neonates receiving mechanical ventilation than in neonates breathing spontaneously. Our objectives were to study the frequency of bedside assessments for continuous pain as well as the individual and institutional factors determining the use of these assessments in routine NICU care. We report assessments of continuous pain in 6648 neonates studied in 243 NICUs from 18 European countries.

\section{METHODS}

\section{Study design}

European-pain-audit-in-neonates (EUROPAIN) was a prospective observational study of clinical practices related to sedation/analgesia and was designed using STROBE guidelines (26). The website (www.europainsurvey.eu) stored multilingual study materials, instructive videos on completing online questionnaires, documents, progress reports and the complete study protocol (http://www. europainsurvey.eu/europain-survey-protocol/). Website links connected authorised users to secure servers (hosted by Voozanoo $^{\circledR}$; Epiconcept, Paris, France) for data entry into standardised questionnaires.

\section{Participating centres}

NICU nurses or physicians volunteered as National Principal Investigators (NPIs); each NPI invited participation of all NICUs in their country and provided data on national pain guidelines for neonates. Level III NICUs initiating and performing the full period of mechanical ventilation were eligible for participation; NICUs unable to provide the full range of Level III care were not eligible. A study nurse, data quality manager and physician coordinator were appointed for each unit, providing information on NICU characteristics and local sedation/analgesia protocols. NICUs were queried about the presence of nurses or physicians with specialised knowledge and/or commitment to neonatal pain management; these clinicians were labelled as physician or nurse pain champions.

\section{Data collection}

During prespecified enrolment periods, all NICU admissions up to 44 weeks postconceptual age were included. Demographic data, modes of ventilation, use of continuous or intermittent sedation/analgesia or neuromuscular blockers, and assessments of continuous pain for each neonate were collected prospectively during the first 28 days of NICU admission, or until death, or hospital discharge. NICUs were specifically asked to record pain assessments performed with pain tools designed for measuring prolonged, continuous pain; two examples of these scales were given on the data collection sheets [e.g. Echelle Douleur Inconfort Nouveau-né (EDIN) scale, COMFORT scale] and NICU staff could record any other pain scales they used for continuous pain. Data collection occurred for one month in all participating NICUs; enrolment periods were staggered such that less than forty (40) NICUs enrolled 
patients concomitantly, allowing the coordinating centre to closely monitor data collection at each site. Subject recruitment was authenticated via the NICU admissions logbook. As the study focus was continuous pain (not procedural pain), we specifically collected data on pain assessments carried out with continuous pain tools, recorded which assessment tools were used, and the number of assessments per day. Newborns were included in the pain-assessed group if at least one assessment of continuous pain occurred during their entire NICU stay. NICUs were included in the pain-assessed group if any assessments of continuous pain were recorded from that unit.

\section{Data quality assurance}

A centralised team in Paris monitored completeness and relevance of the data collection. Missing or incongruous data were reported to unit coordinators and locally doublechecked. The monitoring team randomly selected $10 \%$ of subjects (minimum five patients) and the local data quality manager completely double-checked all these patients. If $1 \%$ or more errors occurred, data from another $10 \%$ subjects were double-checked; if $1 \%$ error rates persisted, all data entries from that NICU were double-checked.

\section{Regulatory compliance}

Study protocols and data collection were first approved by the regulatory bodies for Protection of Human Subjects, Data Protection, and Health Research Data Management in France and then approved by similar committees in each country and at some participating sites. Information sheets were given to parents to explain the de-identified data collection, and they were free to decline their child's participation. In some countries (e.g. Norway), parents were required to give consent for participation. The study was registered at ClinicalTrials.gov (\#NCT01694745).

\section{Sample size}

Sample size calculations were based on sedation/analgesia practices (27). We anticipated the participation of at least 15 countries and planned to make comparisons between all countries. We used a chi-square power analysis to calculate the sample size. We expected small differences in sedation or analgesia practices between countries, estimating an effect size (W) of 0.1 for calculations. NCSS-PASS ${ }^{\circledR}$ (version 2008; Kaysville, UT, USA) showed that a sample size of 2303 neonates would achieve 90\% power to detect an effect size of 0.1 with 14 degrees of freedom (15 centres), using a chi-square test with an $\alpha$-error of 0.05 . Estimating a small effect size and requiring $90 \%$ power ensured adequate sample size, thus minimising $\beta$-error.

\section{Data analyses}

Data analyses used SPSS ${ }^{\circledR}$ v17 (Chicago, IL, USA) for descriptive and multivariable analyses. We used a generalised estimating equation (GEE) multivariable model (28) with country or site as the clustering unit. In all neonates, and separately, in ventilated neonates, the clinical factors correlated with NICU pain assessments ( $\mathrm{p} \leq 0.05)$ were included in GEE models. The GEE model fit was assessed by the quasi-likelihood under the independence model criterion (QIC) (29). Results of GEE models are presented as point-estimate odds ratios (OR) with two-sided 95\% confidence intervals (C.I.). To assess associations between pain assessments and use of opioids, sedative hypnotics or general anaesthetics (O-SH-GA), we analysed data from patient-days with or without O-SH-GA using MantelHaenszel chi-square tests, where modes of ventilation ( $\mathrm{TrV}$, $\mathrm{NiV}$ ) by day were the strata. Two-tailed p-values of 0.05 or less were deemed significant.

\section{RESULTS}

\section{Study population}

From October 1, 2012, to June 30, 2013, we enrolled 6648 neonates eligible for this study (Fig. 1). Highest levels of ventilation during the study period classified patients into tracheal ventilation $(\mathrm{TrV}, \mathrm{n}=2138)$, noninvasive ventilation $(\mathrm{NiV}, \mathrm{n}=1493)$ and spontaneous ventilation groups (NoV, $\mathrm{n}=3017$ ); patient characteristics are listed in Table 1 and their distribution among participating countries is listed in Table S1 (Supporting Information). Guidelines for neonatal pain management were available from six countries (33\%) and locally, from 182 NICUs (75\%). The mean (S.D.) period of study participation was 11.9 (9.7) calendar days. Using data from 78740 patient-days of observation, units reported continuous pain assessment in 2838 neonates. Further detailed analyses showed that 725 neonates had pain assessed only using procedural pain tools and were thus excluded from this analysis.

\section{Clinical practices}

Only 2113 of 6648 neonates $(31.8 \%)$ received assessments of continuous pain at least once during their NICU stay, with 2 (1-4) (median [IQR]) pain assessments per day (Table 2). Continuous pain assessments occurred in the NICU for 984 of 2138 (46.0\%) newborns in the TrV, 523 of $1493(35.0 \%) \mathrm{NiV}$ and 606 of 3017 (20.1\%) NoV groups $(\mathrm{p}<0.001)$ (Table 1). To correct for the variable numbers of subjects enrolled from each country, we weighted the pain assessment rates by the number of enrolled newborns per 10000 births in that country (Table S1). The weighted pain assessment rates were $36.0 \%$ for all infants, $46.6 \%$ for $\mathrm{TrV}, 41.6 \%$ for $\mathrm{NiV}$ and $22.3 \%$ for NoV groups, showing substantially similar findings.

Daily pain assessments occurred only in 10.4\% (689/ 6648) patients, including $14 \% \mathrm{TrV}$ patients (300/2138), $10.7 \% \mathrm{NiV}$ patients $(160 / 1493)$ and $7.6 \% \mathrm{NoV}$ patients (229/3017; $\mathrm{p}<0.001)$. Assessments of continuous pain occurred commonly in French $(100 \%)$, Dutch $(80 \%)$ or Belgian (75\%) NICUs, but did not occur in five countries. Across participating countries, pain assessments for continuous pain ranged from $6 \%$ to $90 \%$ in the $\mathrm{TrV}$ group, from $0 \%$ to $87 \%$ in the $\mathrm{NiV}$ group and from $0 \%$ to $84 \%$ in the NoV group (Table 2). On average, individual newborns received 0.8 to 6.7 pain assessments per day (Table 2). 


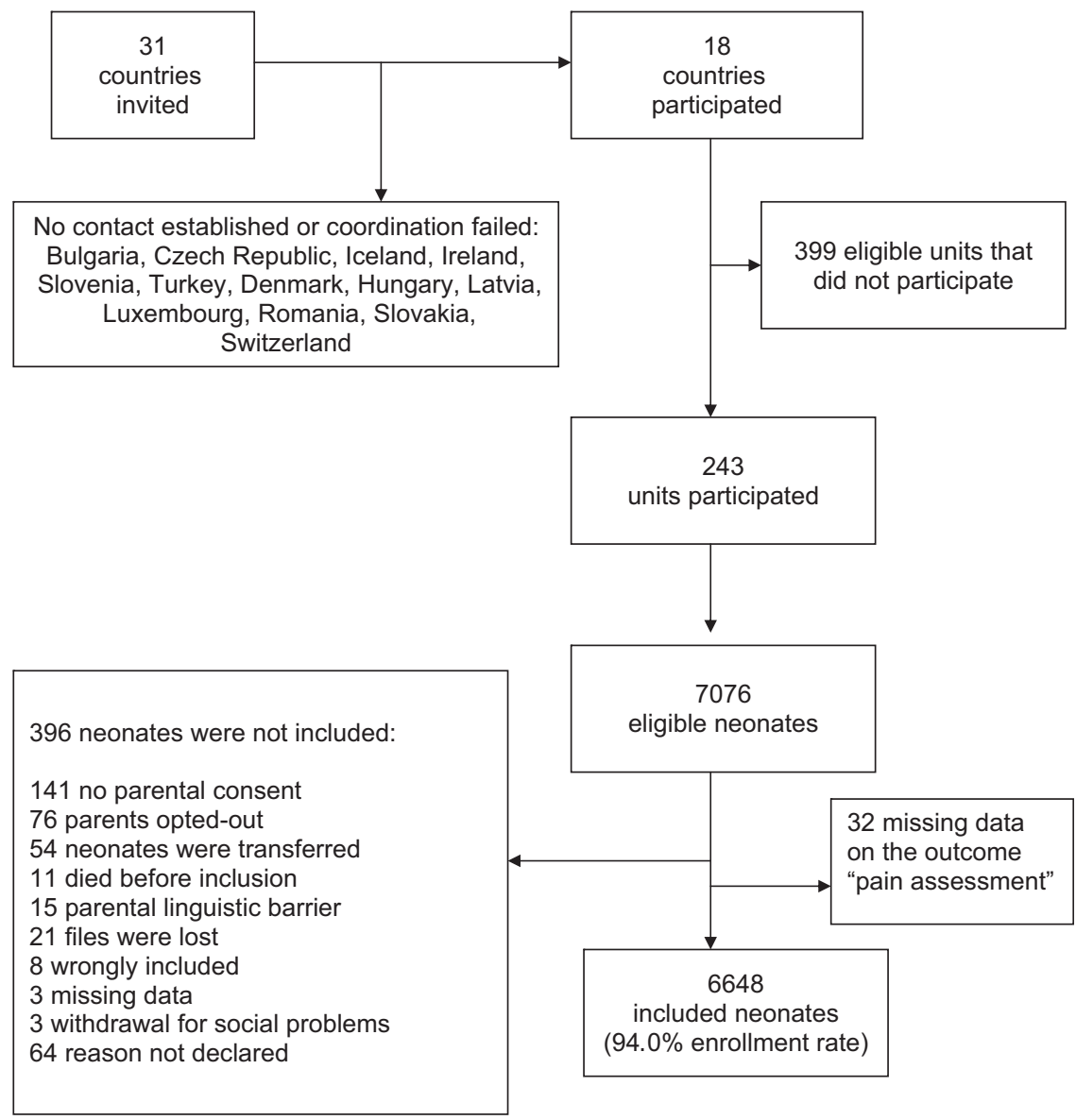

Figure 1 Flow chart of the countries invited, the participating NICUs ('units'), patients assessed and those enrolled in this study. All neonates with pain assessment outcome data were included in our analyses; missing data were not imputed.

Moreover, many different tools were used to assess continuous pain; the EDIN scale was used most frequently (1199/ 2113, 56.7\%); other scores used commonly included the COMFORTneo behaviour scale $(19.7 \%)$, the N-PASS (Neonatal Pain, Agitation and Sedation Scale; 13.2\%), and the COMFORT scale (10.1\%) (Table S2).

\section{NICU characteristics}

NICU characteristics increasing the assessment of continuous pain included the availability of local guidelines, physician or nurse champions, pain consult services, number of surgical admissions and ventilator-days per year (univariable analyses; Table 3). Multivariable GEE models using country as a cluster showed that local pain assessment guidelines (OR: 3.96), nurse pain champions (OR: 2.54) and surgical admissions (OR: 1.01) prompted greater use of continuous pain assessments (all $\mathrm{p}<0.01$ ).

\section{Newborn characteristics}

In univariable analyses, patient characteristics influencing pain assessments in all neonates were as follows: gestational age, birthweight, outborn status, age at admission, Clinical Risk Index for Babies scores (CRIB), one-minute and fiveminute Apgar scores, intubation at admission, surgical condition, respiratory distress syndrome, ventilation status, use of O-SH-GA drugs and hospital length of stay (Table 4). Multivariable modelling using NICUs as cluster showed higher odds of pain assessments associated with prematurity (24-29 weeks OR: 1.92; 30-32 weeks OR: 2.11, both $\mathrm{p}<0.001$ ), intubation at admission (OR: 1.97, $\mathrm{p}<0.001$ ), need for surgery (OR: 2.14, $\mathrm{p}=0.028$ ), noninvasive ventilation (OR: 1.88, $\mathrm{p}<0.001$ ) and use of $\mathrm{O}-\mathrm{SH}-$ GA drugs (OR: 1.99, $\mathrm{p}<0.001$ ), but lower odds with inborn status (OR: 0.67, $\mathrm{p}=0.023$ ) and higher CRIB scores (OR: $0.95, \mathrm{p}=0.013$ ) (Table 4). More frequent pain assessments occurred specifically on those patient-days associated with $\operatorname{TrV}(42.3 \%$ vs. $25.5 \%, \mathrm{p}<0.001)$ or the use of O-SH-GA drugs (45.6\% vs. 26.4\%, p < 0.001) (Fig. 2).

Among tracheally ventilated newborns, patient characteristics influencing continuous pain assessments in univariable analyses included outborn status, CRIB scores, five-minute Apgar scores, intubation at admission, surgical condition, respiratory distress syndrome, use of O-SH-GA and duration of mechanical ventilation. Multivariable GEE modelling showed that the odds of pain assessments increased with intubation at admission (OR: 2.00, $\mathrm{p}<0.001$ ) and O-SH-GA use (OR: 1.45, $\mathrm{p}=0.008)$, but decreased with higher CRIB scores (OR: 0.93, $\mathrm{p}=0.001$ ) (Table 5). 
Table 1 Baseline characteristics and rates of continuous pain assessment

\begin{tabular}{|c|c|c|c|c|}
\hline $\begin{array}{l}\text { Total } \\
\mathrm{n}=6648\end{array}$ & $\begin{array}{l}\text { Tracheal ventilation } \\
\mathrm{n}=2138\end{array}$ & $\begin{array}{l}\text { Noninvasive ventilation } \\
n=1493\end{array}$ & $\begin{array}{l}\text { Spontaneous ventilation } \\
\mathrm{n}=3017\end{array}$ & p Value* \\
\hline $35.0 \pm 4.6$ & $32.7 \pm 5.2$ & $33.8 \pm 3.8$ & $37.3 \pm 3.1$ & $<0.001$ \\
\hline $1045(15.7)$ & 775 (36.3) & $214(14.3)$ & 56 (1.9) & $<0.001^{\dagger}$ \\
\hline $1011(15.2)$ & $360(16.8)$ & 451 (30.2) & $200(6.6)$ & - \\
\hline 1853 (27.9) & $389(18.2)$ & $486(32.6)$ & $978(32.4)$ & - \\
\hline 2737 (41.2) & $613(28.7)$ & $342(22.9)$ & $1782(59.1)$ & - \\
\hline $2385 \pm 1008$ & $1950 \pm 1035$ & $2133 \pm 892$ & $2817 \pm 856$ & $<0.001$ \\
\hline 3753 (56.5) & $1257(58.8)$ & $841(56.3)$ & $1655(54.9)$ & 0.087 \\
\hline 5340 (80.3) & $1457(68.1)$ & 1306 (87.5) & 2577 (85.4) & $<0.001$ \\
\hline 3051 (46.0) & 877 (41.3) & $569(38.1)$ & 1605 (53.3) & $<0.001$ \\
\hline 3577 (54.0) & $1247(58.7)$ & $922(61.8)$ & $1408(46.7)$ & - \\
\hline $1.0(0.3-12.1)$ & $0.8(0.3-8.3)$ & $0.5(0.2-1.7)$ & $3.0(0.4-26.8)$ & $<0.001$ \\
\hline $0(0-2)$ & $2(1-5)$ & $0(0-1)$ & $0(0-0)$ & $<0.001$ \\
\hline $8.4 \pm 1.9$ & $7.4 \pm 2.4$ & $8.5 \pm 1.4$ & $9.0 \pm 1.3$ & $<0.001$ \\
\hline 1372 (20.6) & $1372(64.2)$ & NA & NA & NA \\
\hline $210(3.2)$ & $200(9.4)$ & $3(0.2)$ & $7(0.2)$ & $<0.001$ \\
\hline $8(3-20)$ & $14(6-28)$ & $11(5-26)$ & $5(3-11)$ & $<0.001$ \\
\hline $2113(31.8)$ & $984(46.0)$ & $523(35.0)$ & $606(20.1)$ & $<0.001$ \\
\hline
\end{tabular}

\section{Patient characteristics}

Gestational age (weeks, mean \pm SD)

24-29, number (\%)

30-32, number (\%)

33-36, number (\%)

37-42, number (\%)

Birthweight (grams) Mean \pm SD

Male, number (\%)

Inborn, number (\%)

Type of delivery - number (\%)

Vaginal

Caesarean

Age at admission (hr, median (IQR)

CRIB score ${ }^{\ddagger}$ (median (IQR))

Five-minute Apgar Score (mean $\pm \mathrm{SD}$ )

Intubated at admission, number (\%)

Died during study, number (\%)

NICU length of stay (days) $)^{\S}$ (median (IQR))

Pain assessments, number (\%)

Spontaneous ventilation
$n=3017$

Value*

$\mathrm{NICU}=$ Neonatal intensive care unit; NA = Not applicable; CRIB = Clinical Risk Index for Babies.

*Comparisons of the three types of ventilation were made with chi-square (Fisher's exact test when required), ANOVA or Kruskal-Wallis test.

${ }^{\dagger}$ Chi-square for distributions in all strata of gestational ages within the three ventilation groups.

${ }^{\ddagger}$ The CRIB score is a measure of illness severity, based on clinical data from the first 12 hours after birth (range: 0-23, higher scores indicate great risk of mortality).

${ }^{\S}$ Data collection was stopped on day 28 of hospital stay; 1036 (15.6\%) of 6647 neonates were hospitalised for longer than 28 days. Discharge data were missing for one patient.

"Only assessments carried out with continuous, ongoing pain scales were included.

\section{Are pain assessments associated with sedation/analgesia in ventilated newborns?}

In the $\mathrm{TrV}$ group, of the 1287 neonates who received O-SH-GA drugs, $660(51.3 \%)$ had at least one pain assessment during their NICU stay. We analysed 33625 patient-days in this group to test for associations between assessments of continuous pain and the use of O-SH-GA drugs. During $\operatorname{TrV}$, pain assessment rates on patient-days with and without O-SH-GA use were, respectively, 46.0\% vs. $34.7 \%$ ( $\mathrm{p}<0.001$ ), with O-SH-GA use prompting 1.60 fold greater odds of pain assessments (95\% C.I. 1.48-1.73, $\mathrm{p}<0.001$ ). When $\operatorname{TrV}$ group neonates were not receiving mechanical ventilation, pain assessment rates on patientdays with and without O-SH-GA use were, respectively, $41.7 \%$ vs. $24.7 \%(\mathrm{p}<0.001)$, showing 2.18 -fold greater odds of pain assessments (95\% C.I. 1.91-2.48, $\mathrm{p}<0.001)$ with O-SH-GA use. In the TrV group, 1287 neonates who received continuous O-SH-GA drugs; 518 (40.2\%) had pain assessments on the day of starting O-SH-GA and another $100(7.8 \%)$ had pain assessments on the day after starting O-SH-GA drugs.

On analysing 21130 patient-days in the NiV group, rates of bedside pain assessments on patient-days with and without O-SH-GA were, respectively, $36.8 \%$ vs. $29.9 \%$ $(\mathrm{p}=0.024)$ while receiving $\mathrm{NiV}$, and $19.6 \%$ vs. $13.9 \%$ while not receiving $\mathrm{NiV}(\mathrm{p}=0.092)$. The odds of continuous pain assessments were 1.40-fold greater (95\% C.I. 1.10-1.78) on patient-days associated with O-SH-GA use.

\section{DISCUSSION}

\section{Statement of principal findings}

We report the first international, prospective observational study investigating neonatal pain assessment practices in European NICUs. Neonatal pain guidelines recommend routine pain assessments scheduled every 4-6 hours each day $(30,31)$, but only $10 \%$ of neonates received daily assessments of continuous pain. More than two-thirds of all neonates and more than half of tracheally ventilated neonates received no assessments of continuous pain during their entire NICU stay! This reveals a significant gap between recommended $(30,31)$ and bedside practices for neonatal pain assessment. Pain assessments varied from $0 \%$ to $100 \%$ across the three ventilation groups, the 243 NICUs, and the 18 countries; therefore, we identified the individual and institutional characteristics associated with pain assessments. We used GEE methods for multivariable analyses to incorporate binary and continuous data, weighted and nonweighted observations, as well as more complex interactions between the variables in our database (32). NICUs with local pain management guidelines, nursing champions, and increased surgical admissions 
Table 2 Frequency of continuous pain assessments in participating countries and by ventilation group

\begin{tabular}{|c|c|c|c|c|c|c|c|}
\hline \multirow[b]{2}{*}{ Country } & \multirow[b]{2}{*}{$\begin{array}{l}\text { Centres performing } \\
\text { pain assessment* } \\
\text { Number }(\%)\end{array}$} & \multirow{2}{*}{$\begin{array}{l}\text { Number of pain } \\
\text { assessments per } \\
\text { neonate per day }{ }^{\dagger} \\
\text { Mean (SD) }\end{array}$} & \multicolumn{4}{|c|}{ Neonates with at least one pain assessment during NICU stay, number (\%) } & \multirow[b]{2}{*}{ p Value } \\
\hline & & & $\begin{array}{l}\text { All neonates } \\
\mathrm{n}=6648\end{array}$ & $\begin{array}{l}\text { Tracheal } \\
\text { ventilation } \\
\mathrm{n}=2138\end{array}$ & $\begin{array}{l}\text { Noninvasive } \\
\text { ventilation } \\
n=1493\end{array}$ & $\begin{array}{l}\text { Spontaneous } \\
\text { ventilation } \\
\mathrm{n}=3017\end{array}$ & \\
\hline Austria & $1 / 4(25.0)$ & $0.8(0.7)$ & $31 / 73(42.5)$ & $8 / 22(36.4)$ & $20 / 32(62.5)$ & $3 / 19(15.8)$ & 0.004 \\
\hline Belgium & $3 / 4(75.0)$ & $1.3(1.4)$ & $29 / 128(22.7)$ & $16 / 37(43.2)$ & $9 / 51(17.6)$ & $4 / 40(10.0)$ & 0.001 \\
\hline Cyprus & $0 / 1(0.0)$ & 0 & $0 / 84(0.0)$ & 0 & 0 & 0 & - \\
\hline Estonia & $0 / 2(0.0)$ & 0 & $0 / 22(0.0)$ & 0 & 0 & 0 & - \\
\hline Finland & $1 / 6(16.7)$ & $2.3(0.8)$ & 18/201 (9.0) & $3 / 52(5.8)$ & $5 / 45(11.1)$ & $10 / 104$ (9.6) & 0.619 \\
\hline France & $34 / 34(100.0)$ & $2.6(1.8)$ & $779 / 885$ (88.0) & 445/493 (90.3) & $192 / 222(86.5)$ & $142 / 170(83.5)$ & 0.047 \\
\hline Germany & $1 / 4(25.0)$ & $0.8(0.8)$ & $2 / 126(1.6)$ & $2 / 29(6.9)$ & $0 / 17(0.0)$ & $0 / 80(0.0)$ & 0.033 \\
\hline Greece & $0 / 13(0.0)$ & 0 & $0 / 455(0.0)$ & 0 & 0 & 0 & - \\
\hline Italy & $20 / 28(71.4)$ & $1.4(1.4)$ & $236 / 422(55.9)$ & $93 / 131$ (71.0) & $84 / 150(56.0)$ & $59 / 141$ (41.8) & $<0.001$ \\
\hline Lithuania & $0 / 1(0.0)$ & 0 & $0 / 45(0.0)$ & 0 & 0 & 0 & - \\
\hline Malta & $0 / 1(0.0)$ & 0 & $0 / 28(0.0)$ & 0 & 0 & 0 & - \\
\hline The Netherlands & $4 / 5(80.0)$ & $1.6(0.8)$ & $166 / 208(79.8)$ & $56 / 69(81.2)$ & $55 / 68$ (80.9) & $55 / 71$ (77.5) & 0.832 \\
\hline Norway & $3 / 16(18.8)$ & $1.1(0.9)$ & $29 / 334(8.7)$ & $3 / 35(8.6)$ & $7 / 94(7.4)$ & $19 / 205(9.3)$ & 0.874 \\
\hline Poland & $2 / 8(25.0)$ & $2.7(1.3)$ & $30 / 83(36.1)$ & $11 / 50(22.0)$ & $14 / 25(56.0)$ & $5 / 8(62.5)$ & 0.004 \\
\hline Portugal & $10 / 14(71.4)$ & $3.1(2.6)$ & $140 / 236(59.3)$ & $36 / 55(65.5)$ & $29 / 54(53.7)$ & $75 / 127(59.1)$ & 0.457 \\
\hline Spain & $5 / 30(16.7)$ & $1.8(1.3)$ & $28 / 468(6.0)$ & $14 / 202(6.9)$ & $8 / 149(5.4)$ & $6 / 117(5.1)$ & 0.750 \\
\hline Sweden & $2 / 6(33.3)$ & $6.7(3.9)$ & $27 / 160(16.9)$ & $21 / 38(55.3)$ & $4 / 47(8.5)$ & $2 / 75(2.7)$ & $<0.001$ \\
\hline United Kingdom & $30 / 66(45.5)$ & $5.7(6.0)$ & $598 / 2690(22.2)$ & $276 / 713(38.7)$ & $96 / 438(21.9)$ & $226 / 1539(14.7)$ & $<0.001$ \\
\hline Total & $116 / 243(47.7)$ & $3.3(3.9)$ & $2113 / 6648$ (31.8) & $984 / 2138(46.0 \%)$ & $523 / 1493$ (35.0) & $606 / 3017(20.1)$ & $<0.001$ \\
\hline
\end{tabular}

*At least in one neonate.

${ }^{\dagger}$ In neonates who had at least 1 assessment for continuous pain during their entire NICU stay.

${ }^{\ddagger}$ Comparisons of three types of ventilation using chi-square tests.

performed assessments of continuous pain more frequently. Pain assessments also occurred more frequently among newborns $<32$ weeks gestational age, those requiring surgery, mechanical ventilation, use of opioids (morphine, fentanyl, sufentanil), sedatives-hypnotics (midazolam, lorazepam, barbiturates) or general anaesthetics (ketamine, propofol) in the NICU. Assessments of continuous pain in ventilated neonates were more likely on the patient-days associated with use of opioids, sedatives/hypnotics or general anaesthetics (Fig. 2).

\section{Strengths and weaknesses of this study}

Assessments of continuous pain were associated with greater severity of illness, because they occurred more frequently in newborns with extreme prematurity, those requiring intubation at admission, or surgical interventions, or tracheal and noninvasive ventilation during their NICU stay. Neonates with higher CRIB scores, however, had less frequent pain assessments. This discrepancy may occur because the CRIB score was designed to measure risk of mortality from clinical factors at the time of NICU admission (33), and it does not reflect severity of illness during the entire NICU stay.

Pain assessments occurred more frequently following use of O-SH-GA drugs among all neonates, tracheally ventilated neonates and noninvasively ventilated neonates. Pain assessments were also more likely on the patient-days when these drugs were used (Fig. 2). Even among newborns receiving continuous infusions of O-SH-GA drugs, however, only $48 \%$ had assessments of continuous pain on the same day or the day after starting these drugs. To limit the data collection burden on participating NICUs, the timing of pain assessments or drug administration was not recorded; therefore, our data do not permit more detailed analyses of the relationships between pain assessments and therapeutic decision-making.

Another limitation could be that participating NICUs do not represent national practices in each country. Because of differences in the number of participating NICUs (and subjects) across the different countries (Table S1), we performed sensitivity analyses to weight the pain assessment results with the proportion of neonates enrolled per 10000 live births in each country. The results of these analyses were substantially unchanged, thus suggesting external validity for the European countries participating in this study. While we acknowledge this limitation, other than mandatory data collection (often with suspect data quality), we had no practical options to overcome this limitation. Level III NICUs with relatively high patient volumes participated in all countries, not only representing a snapshot of the most advanced practices in each country, but also allowing us to sample on average about $0.15 \%$ of all births per year (Table S1).

A putative 'Hawthorne effect' (34) could have altered pain assessment practices during study enrolment, but this would be difficult to maintain during 24/7 data collection over a one-month period. Another limitation is that these results were based on documentation of bedside pain assessments. 
Table 3 NICU characteristics associated with assessments of continuous pain

\begin{tabular}{|c|c|c|c|c|c|}
\hline & \multicolumn{5}{|l|}{ All centres } \\
\hline & \multicolumn{3}{|l|}{ Univariable analysis* } & \multicolumn{2}{|l|}{ Multivariable analysis ${ }^{\dagger}$} \\
\hline & $\begin{array}{l}\text { No pain assessment } \\
(\mathrm{n}=110) \\
\mathrm{n}(\%)^{\ddagger}\end{array}$ & $\begin{array}{l}\text { Pain assessment } \\
(\mathrm{n}=93) \\
\mathrm{n}(\%)^{\ddagger}\end{array}$ & $\begin{array}{l}\text { Chi-square or } \\
\text { Mann-Whitney } \\
\text { U-test }\end{array}$ & Odds ratio $(95 \% \mathrm{Cl})$ & $\mathrm{p}$ Value \\
\hline \multicolumn{6}{|l|}{ Local neonatal pain assessment guidelines in 2012} \\
\hline \multicolumn{6}{|c|}{ Local neonatal pain/sedation treatment guidelines in 2012} \\
\hline No $(n=50)$ & $37(74.0)$ & $13(26.0)$ & \multirow[t]{2}{*}{0.001} & \multirow{2}{*}{ Not Included" } & \\
\hline Yes $(n=153)$ & $73(47.7)$ & $80(52.3)$ & & & \\
\hline \multicolumn{6}{|l|}{ Physician pain champion** } \\
\hline No $(n=127)$ & $83(65.4)$ & $44(34.6)$ & \multirow[t]{2}{*}{$<0.001$} & \multirow[t]{2}{*}{ Not Included ${ }^{\dagger \dagger}$} & \\
\hline Yes $(n=76)$ & $27(35.5)$ & $49(64.5)$ & & & \\
\hline \multicolumn{6}{|l|}{ Hospital pain management team or consult service } \\
\hline No $(n=71)$ & $50(70.4)$ & $21(29.6)$ & \multirow[t]{2}{*}{0.001} & $1^{\S}$ & \multirow[t]{2}{*}{0.510} \\
\hline Yes $(n=132)$ & $60(45.5)$ & $72(54.5)$ & & $1.36(0.55-3.38)$ & \\
\hline \multicolumn{6}{|l|}{ Parents allowed 24 hours a day } \\
\hline No $(n=41)$ & $22(53.7)$ & $19(46.3)$ & \multirow[t]{2}{*}{0.939} & \multirow[t]{2}{*}{ Not Included ${ }^{\star \star}$} & \\
\hline Yes $(n=162)$ & $88(54.3)$ & $74(45.7)$ & & & \\
\hline Number of beds in the unit $(n=203)$ & $20(14-29)^{\S \S}$ & $18(13-26)^{\S \S}$ & 0.352 & Not Included & \\
\hline Number of medical admissions per year $(n=203)$ & $453(300-631)^{\S \S}$ & $384(277-600)^{\S \S}$ & 0.192 & Not Included $\$$ & \\
\hline Number of surgical admissions per year $(n=203)$ & $0(0-30)^{\S \S}$ & $20(0-69)^{\S \S}$ & $<0.001$ & $1.01(1.00-1.02)$ & 0.007 \\
\hline Number of ventilator-days per year $(n=203)$ & $312(115-701)^{\S \S}$ & $672(216-1515)^{\S \S}$ & $<0.001$ & $1.00(1.00-1.00)$ & 0.178 \\
\hline \multicolumn{6}{|c|}{ 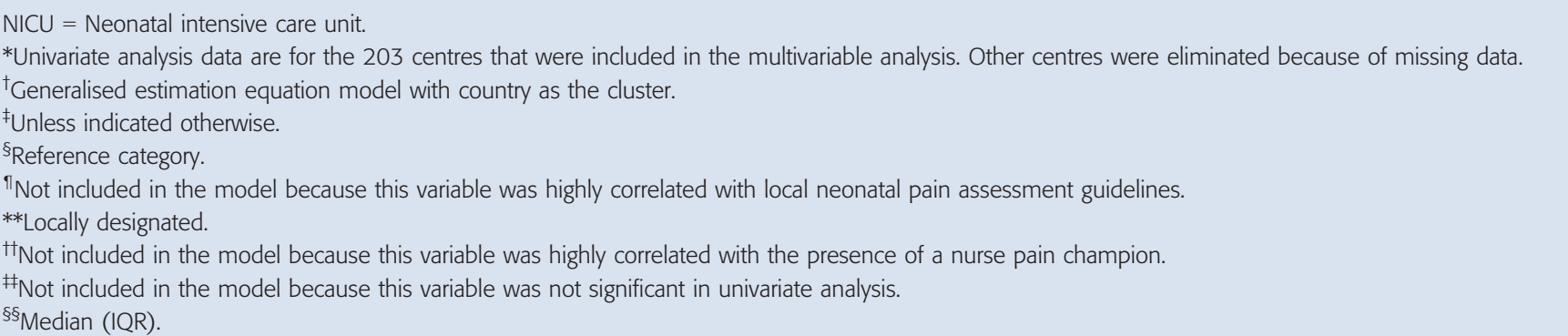 } \\
\hline
\end{tabular}

NICU nurses may rigorously record the use of pain medications, whereas pain assessments and nonpharmacological interventions may be recorded less rigorously. Many NICUs require the regular charting of bedside pain scores every 4 6 hours with the patient's vital signs. Data collection occurred from any existing record, including patient notes, nursing flowsheet at bedside or other sources. We believe that all pain assessments occurring at the bedside were recorded in our data collection.

Despite the aforementioned limitations, this is the largest study to date, using prospective data collection, robust data quality assurance, enrolling 94\% of all eligible neonates, accounting for all nonenrolled neonates, while overcoming the language, cultural and research regulatory barriers in 18 countries. Thus, it represents the most comprehensive glimpse into the current bedside pain assessment practices in NICUs.

\section{Strengths and weaknesses in relation to other studies}

NICU nurses are primarily responsible for bedside pain assessments in neonates although some have questioned the utility (35) and validity (36) of these assessments. An alternative approach calls for using pain scores for research studies and pain detection for clinical care (37), but it still does not address the need for assessing continuous pain. Well-known weaknesses in the current paradigm for neonatal pain assessments include their subjectivity, low inter-rater reliability and other concerns (10,15,18,38-40). Sedatives and neuromuscular blockers may also mask the behavioural signs of continuous pain (27). Despite the weaknesses and caveats of neonatal pain assessment tools, we posit that routine assessments of continuous pain will improve individualised pain management $(18,41)$.

Of the currently available pain assessment tools, only the EDIN (22), COMFORTneo (24), ALPS-Neo (Astrid 
Table 4 Patient characteristics associated with assessments of continuous pain in all neonates

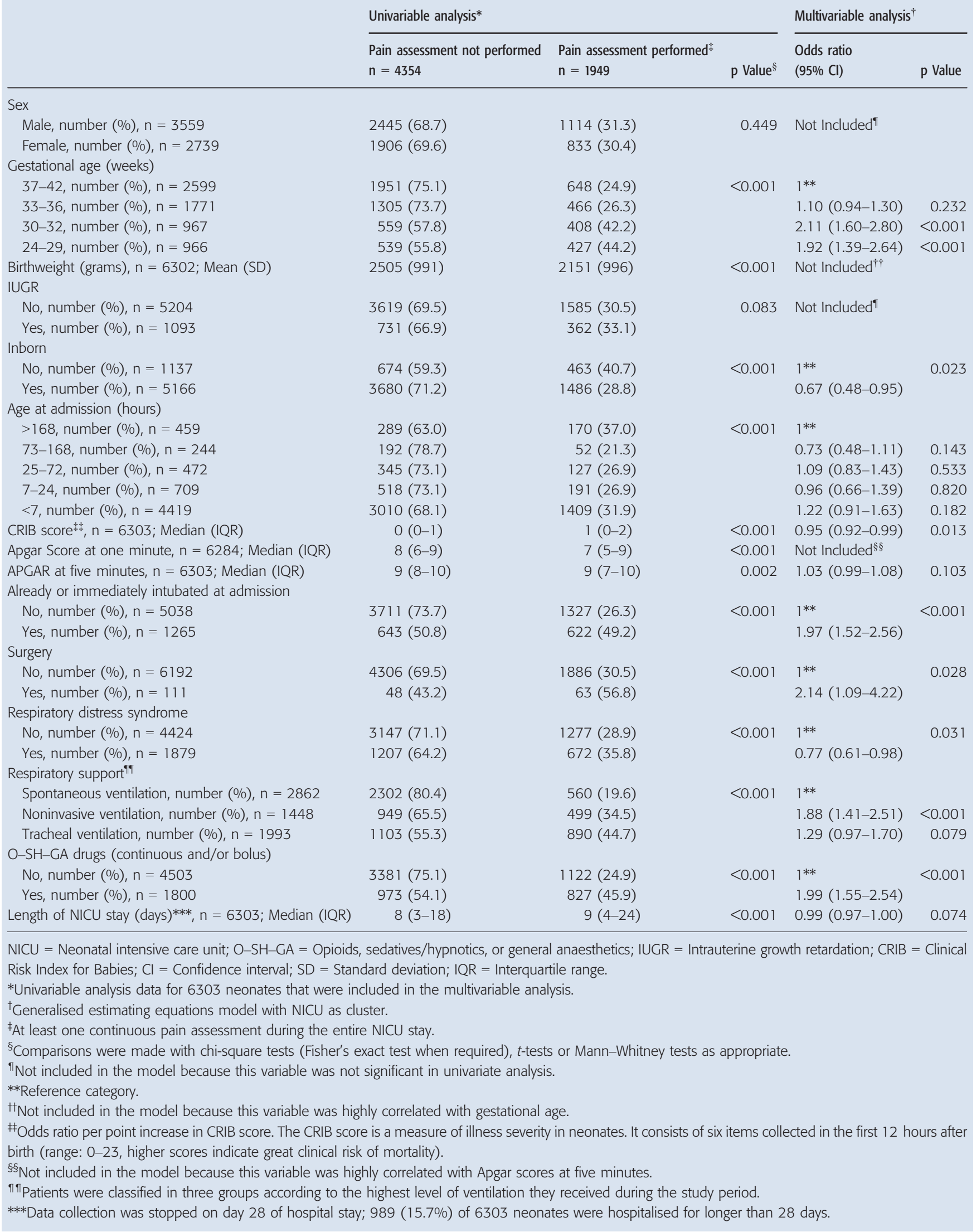




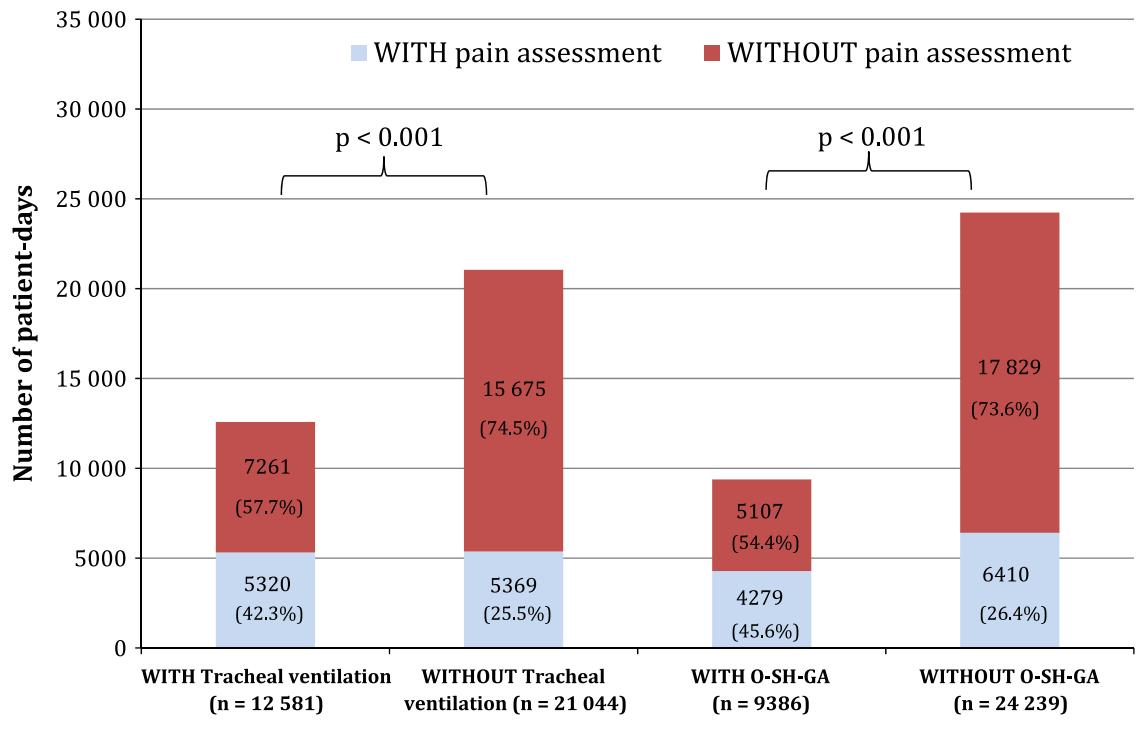

Subgroups of 33,625 patient-days with or without tracheal ventilation or O-SH-GA use

Figure 2 Frequency of assessments of continuous pain in the tracheal ventilation (TrV) group on patient-days with or without TrV, or with or without the use of O-SHGA drugs. Data from all ventilated neonates $(n=2138)$ were analysed for the 33625 patient-days of observation. $\mathrm{p}$ Values are based on chi-square tests.

Lindgren's Children's Hospital Pain Scale) (23) and the Neonatal Pain, Agitation and Sedation Scale (N-PASS) (42) were designed to assess continuous pain. To develop the EDIN scale, a panel of experts assessed video recordings of neonates with prolonged pain (e.g. necrotising enterocolitis, postoperative pain) for behavioural indicators of pain (facial activity, body movements, quality of sleep, quality of contact with nurses, consolability). It showed acceptable inter-rater reliability, high internal consistency and significant differences between painful and nonpainful conditions, suggesting preliminary construct validity (22). van Dijk et al. adapted COMFORT scale to develop the COMFORTneo scale for newborns with prolonged pain, which appeared to be a promising tool but requires additional studies to support its validity and clinical utility (24). Similarly, Lundqvist et al. adapted the ALPS-1 scale to develop the ALPS-Neo using five behavioural parameters, including facial expressions, breathing pattern, limb muscle tone, hand/foot activity and level of activity to assess continuous pain in neonates (23). They reported acceptable reliability and face validity, although this tool also requires further validation (23). The N-PASS was designed to assess pain and sedation in neonates with postoperative pain or mechanical ventilation and showed adequate inter-rater reliability, convergent and discriminate validity (42), and clinical utility (43). It was later applied to acute pain with similar results (44). Despite the availability of these scales, continuous pain lacks a consistent definition.

Pillai-Riddell et al. (16) interviewed experienced clinicians to define chronic pain in infancy. Their qualitative analysis suggested that inability to settle, social withdrawal, constant grimacing, tense body, hypo- or hyper-reactivity to acute pain, dysregulated sleep or feeding patterns could serve as potential indicators for chronic pain. Secondary analyses from the NEOPAIN trial suggested that facial expressions of pain, high activity levels, poor response to handling and poor ventilator synchronicity were most frequently associated with continuous pain in preterm newborns $\leq 32$ weeks of gestation (15). Although both studies found some overlap with EDIN parameters, they were not used to develop novel assessment tools for persistent pain in neonates.

Although the PIPP and CRIES scales have been tested in settings of postoperative pain, their construct validity as tools to assess continuous pain remains unproven $(25,45)$. Our finding of infrequent assessments of continuous pain is not surprising in the context of few assessment tools available and relative lack of across-the-board validity data for these methods $(18,41)$. Furthermore, the validity of these scales when translated into the different languages spoken in the participating countries has not been established.

\section{Meaning of the study}

Infrequent and highly variable assessments of continuous pain in newborns may contribute to analgesic complications (46), oversedation (47) or tolerance/withdrawal (48). Given the limitations and controversies reviewed above, the variability noted in this study is not unexpected and mirrors similar findings in adult patients (49). Our data show that local NICU guidelines and local nurse champions substantially increased the odds for pain assessment, whereas the availability of pain consult services did not (Table 3). All NICUs should develop standardised approaches for neonatal pain and identify experienced nurses to lead this effort. Most NICUs had local neonatal pain guidelines, but only a third of the participating countries had national guidelines. Policymakers at the European Medicines Agency and/or European professional societies should consider developing neonatal pain guidelines for NICUs in all European countries. 


\section{Table 5 Patient characteristics associated with assessments of continuous pain assessments in tracheally ventilated newborns}

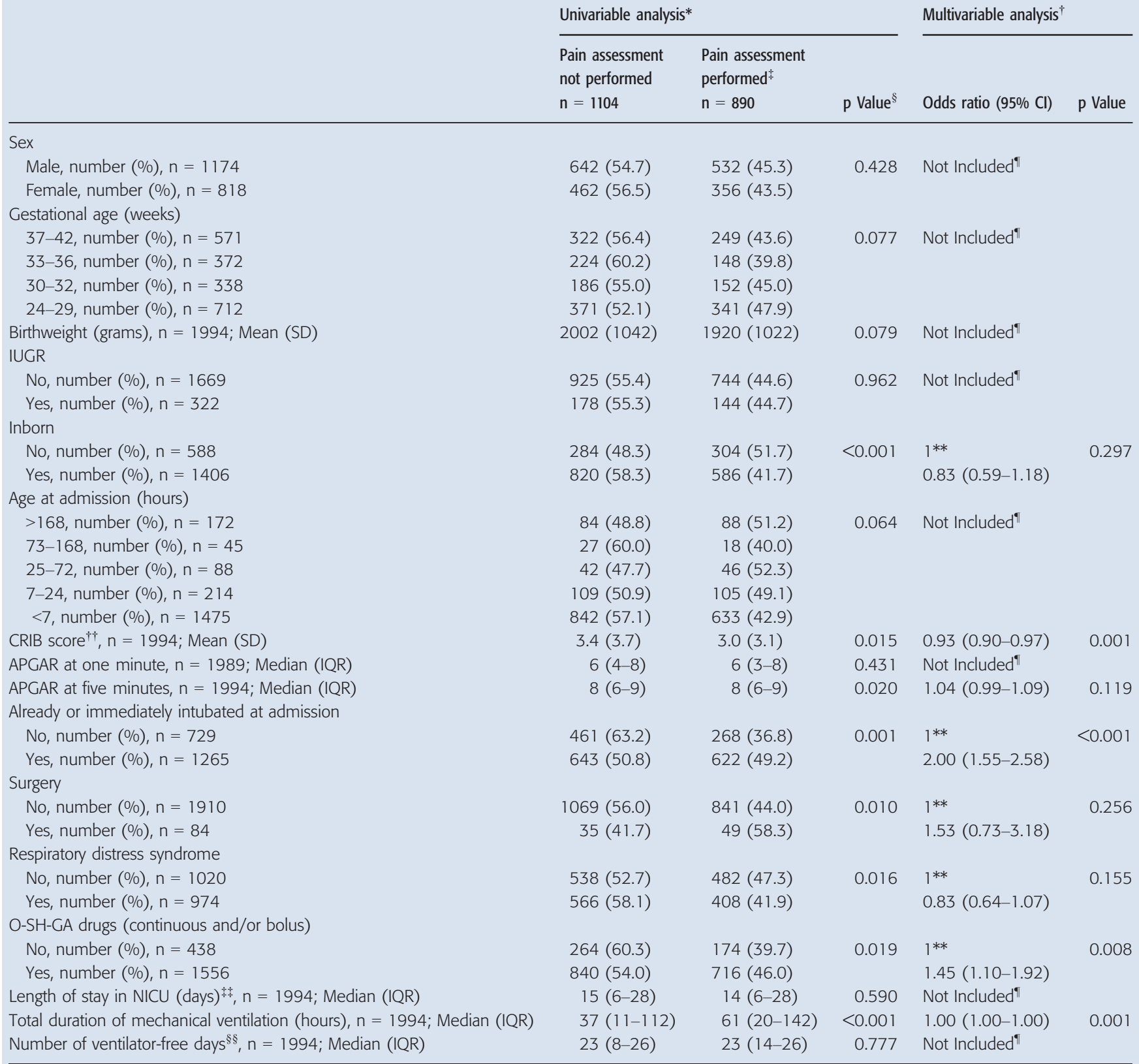

$\mathrm{NICU}=$ Neonatal intensive care unit; O-SH-GA = Opioids, sedatives/hypnotics or general anaesthetics; IUGR = Intrauterine growth retardation; CRIB = Clinical Risk Index for Babies; $\mathrm{Cl}=$ Confidence interval; $\mathrm{SD}=$ Standard deviation; IQR = Interquartile range.

*Univariable analysis data for the 1994 neonates that were included in the multivariable analysis.

${ }^{\dagger}$ Generalised estimation equation model with NICU as cluster.

${ }^{\ddagger}$ At least one assessment of continuous pain during the NICU stay.

${ }^{\S}$ Comparisons were made with chi-square tests (Fisher's exact test when required), $t$-tests or Mann-Whitney tests as appropriate.

"Not included in the model because this variable was not significant in the univariable analysis.

**Reference category.

"IOdds ratio per point increase in CRIB score. The CRIB score is a measure of illness severity in neonates. It consists of six items collected in the first 12 hours after birth (range: 0-23, higher scores indicate great clinical risk of mortality).

\#Data collection was stopped on day 28 of hospital stay: 566 (28.4\%) of 1994 neonates were hospitalised for longer than 28 days.

$\S \S$ Ventilator-free days were defined as the number of calendar days from the time of tracheal extubation to day 28 after NICU admission. If a neonate was reintubated and subsequently extubated before day 28 , ventilator-free days were counted from the end of the last period of tracheal intubation. If a neonate was still receiving tracheal ventilation on day 28 or had died before day 28 , then 0 ventilator-free days were noted. For neonates discharged before day 28 of admission, ventilator-free days were zero if the neonate was still intubated at discharge (transfer) and ventilator-free days were counted from the time of tracheal extubation to day 28 after NICU admission if the neonate was already extubated at discharge. 
Unanswered questions and future research

Neonatal pain research has been focused on the acute episodic pain associated with skin-breaking procedures $(4,11,12,36,37,50)$. We suggest the need for a paradigm shift in neonatal pain research, paying greater attention to prolonged or continuous pain in newborns. First, we need to reach consensus on the taxonomy and definitions of various pain terms applied to neonates. Achieving consensus on these terms may lead to developing newer assessment tools, examining the validity and clinical utility of currently available and novel methods, and using these methods to determine the need for, and the efficacy of therapeutic approaches treating continuous pain in neonates. Neurophysiological approaches (51) such as near-infrared spectroscopy, electroencephalography or functional MRI can display pain-induced activity in the brain $(2,52)$, whereas skin conductance, heart rate variability or pupillometry can detect autonomic activity in neonates $(41,53)$. If these approaches lead to reliable and clinically useful pain measures, they may allow an independent validation of observer-dependent pain assessment scales for both episodic and continuous pain.

Recent guidelines from American Academy of Pediatrics state that validated pain assessment tools should be used consistently to initiate and monitor the effectiveness of analgesic interventions (30). Reliable and objective measures of continuous pain in newborns must be defined, developed, extensively validated and used regularly at the bedside, to improve the safety and efficacy of analgesics or other therapies used for treating neonatal pain. By avoiding the acute and long-term effects of both unrelieved pain and unnecessary analgesia in newborns, we can optimise sedation/analgesia, improve clinical outcomes and reduce painrelated suffering in newborns.

\section{ACKNOWLEDGEMENTS}

This study was supported by the European Community's Seventh Framework Programme grant no. 223767. This funding agency did not participate in the design and conduct of the study; collection, management, analysis and interpretation of the data; and preparation, review or approval of the manuscript. Authors had full access to all study data and take responsibility for data integrity and the accuracy of data analyses. We thank the physicians, nurses and other healthcare providers at participating institutions for their contributions and parents who allowed us to gather data related to their infants. We sincerely acknowledge Colin Gentile, Juliana Guilheri, Kébé Korka, Alicia Marzouk, Liliane Peneau, Astrid Polaert, Nathalie Quiniou, Dalila Selmane, Dienaba Sylla, Tony Toulorge and Stephen Ulric-Gervaise for special assistance with data collection.

\section{COMPETING INTEREST STATEMENT}

All authors have completed the ICMJE uniform disclosure form and declare: no support from any organisation for the submitted work; no financial relationships with any organisations that might have an interest in the submitted work in the previous three years, and no other relationships or activities that could appear to have influenced the submitted work.

\section{References}

1. Walker SM. Neonatal pain. Paediatr Anaesth 2014; 24: 39-48.

2. Goksan S, Hartley C, Emery F, Cockrill N, Poorun R, Moultrie F, et al. fMRI reveals neural activity overlap between adult and infant pain. eLife 2015; 4: e06356.

3. Ranger M, Grunau RE. Early repetitive pain in preterm infants in relation to the developing brain. Pain Manag 2014; 4: 57-67.

4. Vinall J, Grunau RE. Impact of repeated procedural painrelated stress in infants born very preterm. Pediatr Res 2014; 75: 584-7.

5. Bhandari V, Bergqvist LL, Kronsberg SS, Barton BA, Anand KJS. Morphine administration and short-term pulmonary outcomes among ventilated preterm infants. Pediatrics 2005; 116: 352-9.

6. Bellu R, de Waal KA, Zanini R. Opioids for neonates receiving mechanical ventilation. Cochrane Database Syst Rev 2008; Issue 1: CD004212.

7. Duerden EG, Guo T, Dodbiba L, Chakravarty MM, Chau V, Poskitt K, et al. Midazolam dose correlates with abnormal hippocampal growth and neurodevelopmental outcome in preterm infants. Ann Neurol 2016; 79: 548-59.

8. Zwicker JG, Miller SP, Grunau RE, Chau V, Brant R, Studholme C, et al. Smaller cerebellar growth and poorer neurodevelopmental outcomes in very preterm infants exposed to neonatal morphine. J Pediatr 2016; 172: 81-7.e2.

9. Ferguson SA, Ward WL, Paule MG, Hall RW, Anand KJS. A pilot study of preemptive morphine analgesia in preterm neonates: effects on head circumference, social behavior, and response latencies in early childhood. Neurotoxicol Teratol 2012; 34: 47-55.

10. Anand KJS, Aranda JV, Berde CB, Buckman S, Capparelli EV, Carlo W, et al. Summary proceedings from the neonatal paincontrol group. Pediatrics 2006; 117: S9-22.

11. Hatfield LA, Ely EA. Measurement of acute pain in infants: a review of behavioral and physiological variables. Biol Res Nurs 2015; 17: 100-11.

12. Cong X, McGrath JM, Cusson RM, Zhang D. Pain assessment and measurement in neonates: an updated review. Adv Neonatal Care 2013; 13: 379-95.

13. Sharek PJ, Powers R, Koehn A, Anand KJS. Evaluation and development of potentially better practices to improve pain management of neonates. Pediatrics 2006; 118(Suppl. 2): S78-86.

14. Walden M, Carrier C. The ten commandments of pain assessment and management in preterm neonates. Crit Care Nurs Clin North Am 2009; 21: 235-52.

15. Boyle EM, Freer Y, Wong CM, McIntosh N, Anand KJS. Assessment of persistent pain or distress and adequacy of analgesia in preterm ventilated infants. Pain 2006; 124: 87-91.

16. Pillai Riddell RR, Stevens BJ, McKeever P, Gibbins S, Asztalos L, Katz J, et al. Chronic pain in hospitalized infants: health professionals' perspectives. J Pain 2009; 10: 1217-25.

17. van Ganzewinkel CJ, Anand KJS, Kramer BW, Andriessen P. Chronic pain in the newborn: toward a definition. Clin J Pain 2014; 30: 970-7.

18. Pillai Riddell R, Fitzgerald M, Slater R, Stevens B, Johnston C, Campbell-Yeo M. Using only behaviours to assess infant pain: a painful compromise? Pain 2016; 157: 1579-80.

19. Holsti L, Grunau RE, Oberlander TF, Whitfield MF. Prior pain induces heightened motor responses during clustered care in preterm infants in the NICU. Early Hum Dev 2005; 81: 293302. 
20. Osman M, Elsharkawy A, Abdel-Hady H. Assessment of pain during application of nasal-continuous positive airway pressure and heated, humidified high-flow nasal cannulae in preterm infants. J Perinatol 2015; 35: 263-7.

21. Decembrino L, Ruffinazzi G, Russo F, Manzoni P, Stronati M. Monolateral suppurative parotitis in a neonate and review of literature. Int J Pediatr Otorhinolaryngol 2012; 76: 930-3.

22. Debillon T, Zupan V, Ravault N, Magny JF, Dehan M. Development and initial validation of the EDIN scale, a new tool for assessing prolonged pain in preterm infants. Arch Dis Child Fetal Neonatal Ed 2001; 85: F36-41.

23. Lundqvist P, Kleberg A, Edberg AK, Larsson BA, HellstromWestas L, Norman E. Development and psychometric properties of the Swedish ALPS-Neo pain and stress assessment scale for newborn infants. Acta Paediatr 2014; 103: 833-9.

24. van Dijk M, Roofthooft DW, Anand KJS, Guldemond F, de Graaf J, Simons S, et al. Taking up the challenge of measuring prolonged pain in (premature) neonates: the COMFORTneo scale seems promising. Clin J Pain 2009; 25: 607-16.

25. McNair C, Ballantyne M, Dionne K, Stephens D, Stevens B. Postoperative pain assessment in the neonatal intensive care unit. Arch Dis Child Fetal Neonatal Ed 2004; 89: F537-41.

26. Bastuji-Garin S, Sbidian E, Gaudy-Marqueste C, Ferrat E, Roujeau JC, Richard MA, et al. Impact of STROBE statement publication on quality of observational study reporting: interrupted time series versus before-after analysis. PLoS One 2013; 8: e64733.

27. Carbajal R, Eriksson M, Courtois E, Boyle E, Avila-Alvarez A, Andersen RD, et al. Sedation and analgesia practices in neonatal intensive care units (EUROPAIN): results from a prospective cohort study. Lancet Respir Med 2015; 3: 796-812.

28. Zeger SL, Liang KY, Albert PS. Models for longitudinal data: a generalized estimating equation approach. Biometrics 1988; 44: 1049-60.

29. Pan W. Akaike's information criterion in generalized estimating equations. Biometrics 2001; 57: 120-5.

30. Keels E, Sethna NF, Committee on Fetus \& Newborn, Section on Anesthesiology \& Pain Medicine.. Prevention and management of procedural pain in the neonate: an update. Pediatrics 2016; 137: 1-13.

31. Anand KJS, International Evidence-Based Group for Neonatal Pain. Consensus statement for the prevention and management of pain in the newborn. Arch Pediatr Adolesc Med 2001; 155: 173-80.

32. Hanley JA, Negassa A, Edwardes MD, Forrester JE. Statistical analysis of correlated data using generalized estimating equations: an orientation. Am J Epidemiol 2003; 157: 364-75.

33. The CRIB. (clinical risk index for babies) score: a tool for assessing initial neonatal risk and comparing performance of neonatal intensive care units. The International Neonatal Network. Lancet 1993; 342: 193-8.

34. Fox NS, Brennan JS, Chasen ST. Clinical estimation of fetal weight and the Hawthorne effect. Eur J Obstet Gynecol Reprod Biol 2008; 141: 111-4.

35. Rohan AJ. The utility of pain scores obtained during 'regular reassessment process' in premature infants in the NICU. J Perinatol 2014; 34: 532-7.

36. Slater R, Cantarella A, Franck L, Meek J, Fitzgerald M. How well do clinical pain assessment tools reflect pain in infants? PLoS Med 2008; 5: e129.

37. Bellieni CV, Tei M, Buonocore G. Should we assess pain in newborn infants using a scoring system or just a detection method? Acta Paediatr 2015; 104: 221-4.

38. Anand KJS. Pain assessment in preterm neonates. Pediatrics 2007; 119: 605-7.
39. Ranger M, Johnston CC, Anand KJS. Current controversies regarding pain assessment in neonates. Semin Perinatol 2007; 31: $283-8$

40. Taylor BJ, Robbins JM, Gold JI, Logsdon TR, Bird TM, Anand KJS. Assessing postoperative pain in neonates: a multicenter observational study. Pediatrics 2006; 118: e992-1000.

41. DiLorenzo M, Pillai Riddell R, Holsti L. Beyond acute pain: understanding chronic pain in infancy. Children (Basel) 2016; 3: pii: E26.

42. Hummel P, Puchalski M, Creech SD, Weiss MG. Clinical reliability and validity of the N-PASS: neonatal pain, agitation and sedation scale with prolonged pain. J Perinatol 2008; 28: 55-60.

43. Hillman BA, Tabrizi MN, Gauda EB, Carson KA, Aucott SW. The Neonatal Pain, Agitation and Sedation Scale and the bedside nurse's assessment of neonates. J Perinatol 2015; 35: 128-31.

44. Hummel P, Lawlor-Klean P, Weiss MG. Validity and reliability of the N-PASS assessment tool with acute pain. J Perinatol 2010; 30: 474-8.

45. Krechel SW, Bildner J. CRIES: a new neonatal postoperative pain measurement score. Initial testing of validity and reliability. Paediatr Anaesth 1995; 5: 53-61.

46. Anand KJS, Hall RW, Desai N, Shephard B, Bergqvist LL, Young TE, et al. Effects of morphine analgesia in ventilated preterm neonates: primary outcomes from the NEOPAIN randomised trial. Lancet 2004; 363: 1673-82.

47. Giordano V, Deindl P, Kuttner S, Waldhor T, Berger A, Olischar M. The Neonatal Pain, Agitation and Sedation Scale reliably detected oversedation but failed to differentiate between other sedation levels. Acta Paediatr 2014; 103: e515-21.

48. Best KM, Asaro LA, Franck LS, Wypij D, Curley MA, Randomized Evaluation of Sedation Titration for Respiratory Failure Baseline Study I. Patterns of sedation weaning in critically ill children recovering from acute respiratory failure. Pediatr Crit Care Med 2016; 17: 19-29.

49. Wadensten B, Frojd C, Swenne CL, Gordh T, Gunningberg L. Why is pain still not being assessed adequately? Results of a pain prevalence study in a university hospital in Sweden. J Clin Nurs 2011; 20: 624-34.

50. Carbajal R, Rousset A, Danan C, Coquery S, Nolent P, Ducrocq $\mathrm{S}$, et al. Epidemiology and treatment of painful procedures in neonates in intensive care units. JAMA 2008; 300: 60-70.

51. Hartley C, Slater R. Neurophysiological measures of nociceptive brain activity in the newborn infant-the next steps. Acta Paediatr 2014; 103: 238-42.

52. Verriotis M, Fabrizi L, Lee A, Cooper RJ, Fitzgerald M, Meek J. Mapping cortical responses to somatosensory stimuli in human infants with simultaneous near-infrared spectroscopy and event-related potential recording. eNeuro 2016; 3: pii: eNeuro.0026-16.2016

53. de Jesus JA, Tristao RM, Storm H, da Rocha AF, Campos D Jr. Heart rate, oxygen saturation, and skin conductance: a comparison study of acute pain in Brazilian newborns. Conf Proc IEEE Eng Med Biol Soc 2011; 2011: 1875-9.

\section{SUPPORTING INFORMATION}

Additional Supporting Information may be found in the online version of this article:

Table S1 Numbers of participating NICUs, patients enrolled, and ventilation groups by country.

Table S2 Numbers of neonates with assessments of prolonged pain by country. 